University of North Florida

UNIVERSITY of

NORTH FLORIDA.

UNF Digital Commons

$1-1993$

\title{
An Institutional Theory Perspective on the DRG Framework, Case- Mix Accounting Systems and Health-Care Organizations
}

\author{
Mark A. Covaleski \\ Mark W. Dirsmith \\ Jeffrey E. Michelman \\ University of North Florida, jeff.michelman@unf.edu
}

Follow this and additional works at: https://digitalcommons.unf.edu/bacc_facpub

Part of the Accounting Commons, and the Finance and Financial Management Commons

\section{Recommended Citation \\ Covaleski, Mark A.; Dirsmith, Mark W.; and Michelman, Jeffrey E., "An Institutional Theory Perspective on the DRG Framework, Case-Mix Accounting Systems and Health-Care Organizations" (1993). Accounting and Finance Faculty Publications. 1. \\ https://digitalcommons.unf.edu/bacc_facpub/1}

This Article is brought to you for free and open access by the Department of Accounting and Finance at UNF Digital Commons. It has been accepted for inclusion in Accounting and Finance Faculty Publications by an authorized administrator of UNF Digital Commons. For more information, please contact Digital Projects. (C) 1-1993 All Rights Reserved

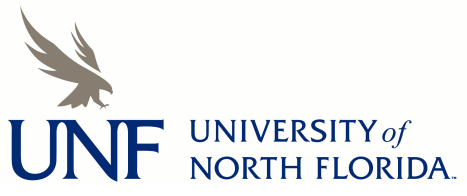




\title{
AN INSTITUTIONAL THEORY PERSPECTIVE ON THE DRG FRAMEWORK, CASE-MIX ACCOUNTING SYSTEMS AND HEALTH-CARE ORGANIZATIONS*
}

\author{
MARK A. COVALESKI \\ University of Wisconsin-Madison \\ MARK W. DIRSMITH \\ Pennsylvania State University \\ and \\ JEFFREY E. MICHELMAN \\ University of Nortb Florida
}

\begin{abstract}
Case-mix accounting systems have been advanced as both reflecting the economic reality that underlies a hospital's various "product lines", as defined by DRG prospective payment categories, and facilitating rational decision making regarding resource acquisition, deployment and use. This article uses the institutional perspective to extend this conceptualization of case-mix accounting systems. The institutional perspective proposes that many elements of organizational structure, like case-mix accounting systems, reflect as much a need to conform to societal expectations of acceptable practice as the technical imperative of fostering rationality. This article also extends institutional theory regarding the issues of power and decoupling by considering institutionalization to be an unfinished process in the health-care context, wherein the active agency of individuals and organizations is subjected to systematic examination. In this specific context, casemix accounting may play a significant role in establishing and perpetuating — not merely supporting — the very social structure of legitimacy, and may consequently be considered an interest-oriented activity having the potential to penetrate and alter the internal operating processes of financially strained hospitals.
\end{abstract}

According to orthodox theorists, the purpose of accounting is to facilitate rational decision making by faithfully representing the task technology or economic reality of the organization (e.g. Ijiri, 1965; Horngren, 1977; Cooper \& Kaplan, 1991; Chandler et al., 1991). Consistent with this perspective, within the health-care sector, case-mix accounting systems, based on diagnostic-related groups (DRGs), ostensibly help hospitals control costs and encourage planning by permitting them to improve the management of their various "product lines". In turn, state and federal governmental agencies as well as private insurers, have developed DRGbased prospective payment frameworks that categorize patients into distinct classes according to the nature and intensity of the services (or "products") they receive (Fetter, A. et al, 1991). Once these services are partitioned, one can use case-mix accounting systems to monitor each "product line" so as to achieve optimum efficiency and effectiveness within the hospital and each subunit, as well as the overall healthcare sector whose costs constitute $12.2 \%$ of the U.S.'s GNP (Fetter \& Freeman, 1986; Warren, 1988; Noble, 1992).

\footnotetext{
* The authors gratefully acknowledge partial research funding support from the University of Wisconsin Industrial Research Program and the Price Waterhouse Foundation. We also thank our three anonymous reviewers for their helpful suggestions.
} 
In contrast with this orthodox perspective, institutional theorists propose that an organization's survival requires it as much to conform to societal norms of acceptable practice as to achieve high levels of production efficiency and effectiveness. Thus, many aspects of an organization's formal structure, policies and procedures serve to demonstrate a conformity with the institutionalized rules and expectations expressed by external constituents (Meyer \& Rowan, 1977; DiMaggio \& Powell, 1983). Accordingly, the DRG framework and case-mix accounting systems may be expected to play heightened, though ritualistic roles in the heavily institutionalized environment of hospitals, where they may be treated as ceremonial systems for creating and affirming order and meaning, for executing procedures in sanctioned ways, and for providing accounts of activities in terms that make them seem reasonable and acceptable to such external constituents as the U.S. Federal government, which is a major payer of health-care costs under the Medicare and Medicaid programs (Scott \& Black, 1986; Scott, 1987; Scott \& Meyer, 1983, esp. pp. 137-152 that provide a discussion of how institutional and technical or economic forces play out differently in such different "sectors" as the health-care context which Meyer \& Rowan, 1977, assert may be especially subject to institutional forces).

A paradox arises here, however, in that these externally directed and relatively simple symbolic displays tend to underrepresent the complexities and indeterminacies in how hospital members actually carry out their assigned tasks. Thus, Meyer \& Rowan (1977; Meyer, 1983 , p. 237 ) reasoned that organizations tend to avoid massive dysfunction by "decoupling" their external image systems from their internal operating processes. More specifically, they observed that "to maintain ceremonial conformity, organizations that reflect institutional rules tend to buffer their formal structures from the uncertainties of technical activities by becoming loosely coupled, building gaps between their formal structures and actual work activities" (1977, p. 341 ).
Despite a growing body of research lending empirical support (recent examples include Fennell \& Alexander, 1987; Covaleski \& Dirsmith, 1988a, b; Levitt \& Nass, 1989; Mezias, 1990), institutional theory has also drawn criticisms, the most prominent of which focus on the issues of power and decoupling. Concerning the first issue, Perrow $(1985,1986)$ asserted that the institutional perspective is inattentive to power and group interest. In response to this criticism, DiMaggio (1988; DiMaggio \& Powell, 1983; Tolbert, 1988; Zucker, 1988a, b) noted an apparent paradox rooted in the two senses in which we have used the term "institutionalization". Institutionalization as antcome places organizational structures and practices beyond the reach of interests and politics; expectations of acceptable practice exist and organizations passively conform to them. By contrast, institutionalization as a process is profoundly political and reflects the relative power of the organized interests and actors who mobilize them.

Providing further insight into the distinction between outcome and process, Clegg (1989a, b) emphasized the importance of interpreting power as a set of rules or disciplinary practices, rather than as some dominant though abstract ideology. He observed a pervasive tendency among researchers to think of power as a "thing", without recognizing that it must also involve the property of influencing social relations through the process of using rules that establish meaning in organization. Key within Clegg's analysis of rules as disciplinary practices is the concept of surveillance:

The concept of "disciplinary practice"... is meant to depict those micro-techniques of power which inscribe and normalize not only individuals but also collective, organized bodies. For instance, any comparative application of performance data or other forms of surveillance would capture the sense of this. Surveillance, whether personal, technical, bureaucratic or legal, is the central issue. Its types may range through forms of, for instance, supervision, routinization, formalization, mechanization and legislation which seek to effect increasing control of employees' behavior, dispositions and embodiment, precisely because they are organization members. ... Through such mechanisms, individuals or bodies collectively, as well as abstract properties of goods and services 
[such as DRG's] may be discriminated and categorized through diverse tactics of rationalization, localized tactics which in their specificity of time, place, aims and objectives reinforce and borrow from each other to form an overall anonymous strategy of discipline. At the more general level of discipline, this will form organizations into discursive locales of competing calculations. Each disciplinary practice, in its applications, will calculate organizational rationality from distinct auspices of power and knowledge (Clegg, 1989b, pp. 100-101).

\section{Like Perrow, Clegg was particularly critical of} the inattention in institutional theory to the nature of rules and social relations of meaning: what becomes institutionalized depends precisely on the power of the organizational actors' translation and use of societal expectations. He urged that such organizational disciplinary practices as case-mix accounting be studied with the use of multiple "disciplinary matrices" - in the current context, the orthodox and institutional perspectives.

Based upon this first major criticism of contemporary institutional theory, our analysis addresses the following research question:

Research question 1 (RQ 1). To what extent are vested interests, and particularly those of the state, served by the development, implementation and modification of institutionalized organizational practices (such as casemix accounting systems)?
The second criticism concerns Meyer \& Rowan's (1977; Meyer, 1983) assertion that organizations tend to avoid massive dysfunction by "decoupling" their external and relatively simplistic image systems from their complex and relatively idiosyncratic internal operating processes. Concerning this issue, Powell (1985, 1988), for example, observed that the central research question concerning the institutional perspective is the extent to which externally directed symbolic displays do, in fact, penetrate and alter internal operating processes. In like manner, Tolbert (1988, pp. 101, 109) pointed to an irony residing in institutional theory. She observed that although this perspective explicitly links macro-level or field-level expectations with micro-level organizational practices (see, for example, DiMaggio \& Powell, 1983, esp. pp. 154-156), research has focused almost exclusively on macro-effects, leaving institutionalized practices within organizations largely unexamined. Tolbert (1988) concluded that, over time, specific organizational rules and practices developed in response to societal expectations become a normative, taken-for-granted part of organizational life, thus transcending their symbolic status and influencing the way external and internal constituents think about and act concerning the organization. ${ }^{1}$

\footnotetext{
${ }^{1}$ One finds this same concern for decoupling in the sociology of professions literature. Here, it has been traditionally argued that because practitioners have internalized the norms and standards of professional practice, the actual imposition of formalized rules and procedures is unnecessary and may even cause professional-bureaucratic conflict and thus impair performance (Hall, 1972; Freidson, 1986; Raelin, 1986). Hence, formalized control may be seen as decoupled from backstage operating processes. More recently, however, Abbott (1988, pp. 323-325) recognized this decoupling as problematic. To begin with, he acknowledged the traditional stance that industrialized countries indeed tend to institutionalize professional expertise in people rather than in structures or rules. But he found a growing trend to institutionalize expertise in organizations, as well, particularly in such professions associated with bureaucracies as medicine, where professional knowledge resides within the structure of the organization itself, and decision autonomy rests not with the individual practitioners, but with those who structure their roles. For example, one could envision the exercise of management control through DRGs and related case-mix accounting systems as a form of organizational structure that dilutes the raison d'être of its professionals - expertise and knowledge. As a result, the practice of formal control and backstage operating processes may become coupled.

In a like manner, Freidson (1986) set out to understand how professional organizations function, how people in them are differentiated by hierarchical position, and how these institutional positions influence the work of creating, communicating and applying expert knowledge. Freidson recognized the differentiation and decoupling that exists between the practitioners and administrative components of such professional bureaucracies as hospitals, and saw power, group interest and decoupling as conditioned by the different duties they perform. Lacking control over policy making and resource allocation, practitioners exercise power over the generation of resources in that they are the ones who meet directly with their clients (or here, patients) and perform the actual service delivery work. Thus, their power stems from
} 
The inherent tension implied in the notion of decoupling can also be found in Clegg's (1989a, b) observation that a theory of power must incorporate both obedience and resistance to rules or disciplinary practices. The threads of power run through the whole nature of decoupling because, as Clegg (1989a, pp. 188-189) said, "The dialectic of resistance resides in the realist view that power necessarily involves reciprocity because it is always constituted within a relational universe of meaning". Reemphasizing the importance of process, Clegg (1989a, p. 199) argued that one must first reproduce the articulation of interests through disciplinary practices before reconstituting the existing power structures. Indeed, this reproduction process is a significant component of power, and its transformation, in turn, represents an effective resistance to power. Moreover, just as the application of power is not always overt, resistance to power need not involve overt conflict. Clegg (1989a, b) observed that there is a general tendency among those subject to power and controlling resources to resist by means of circumventing or diverting to their own ends the existing networks of power rather than by overtly confronting them. He concluded that the issue of decoupling expressed in such terms as "transforming", "circumventing", or "diverting" rules and disciplinary practices - is ultimately mitigated by the relative power of those exercising versus those responding to disciplinary practices.

Drawing upon this second major criticism of contemporary institutional theory, our analysis addresses the following research question:

Research question 2 (RQ 2). To what extent do institutionalized legitimation practices (in the current context, case-mix accounting systems developed in response to DRG payment systems) penetrate and influence internal organizational practices?

The purposes of the remainder of this paper are (a) to extend our understanding of case-mix accounting systems by considering the various institutional processes complicit in their existence and effects beyond merely achieving control over the cost of health-care delivery and faithfully representing the economic reality of hospitals, and (b) to address the two major criticisms of institutional theory concerning the issues of power and decoupling expressed as research questions 1 and 2 , respectively. So as not to be overly mysterious about the product of our analysis, we conclude that (a) such apparently neutral societal and organizational practices as the DRG framework and case-mix accounting systems can have variegated effects on different types of hospitals and areas of medical practice, on what types of patients get served in what types of hospitals, and possibly on who will live and who will die; and (b) the issues of decoupling and power appear to be closely intertwined, with the relative power of different interest groups conditioning the extent to which external imagery is decoupled from backstage processes.

\section{DRGs AND CASE-MIX ACCOUNTING: AN INSTITUTIONAL THEORY PERSPECTIVE}

This section briefly reviews the orthodox perspective regarding DRGs and case-mix accounting in the health-care environment and then juxtaposes this conceptualization using the extended institutional theory perspective with reference to the two research questions set forth in the preceding section.

client contact and fees, and from the performance of work that cannot be wholly commodified. Preoccupied with dealing with the political and economic forces their organizations face, administrators focus on formulating artificially limited, consistent and overly formalized procedural and substantive rules that control the manner in which the professional work is performed. Applying these rules and policies, practitioners transform them according to their judgment and the day-today exigencies of specific client service work. The formal procedures administrators prescribe are applied inconsistently and informally by the practitioners (1986, pp. 226-227), and a decoupling consequentially takes place in the transformation of formal knowledge communicated by administrators in the form of procedural and substantive rules to practitioners. 
The DRG and case-mix accounting

phenomena: the orthodox view

The appearance of DRGs as an approach to regulating and managing hospitals is a recent example of a 45-year effort - dating back to the 1946 passage of the Hospital Survey Construction Act and amplified by the MedicareMedicaid legislation in the early 1960 s - during which the Federal government developed a vested interest in controlling the costs of healthcare delivery. Governmental interest in containing these costs increased with PL 92-603, the Social Security Amendments of 1972, whose purpose was to limit Medicare-Medicaid payments and to establish mechanisms for providing information to effect better control. The National Health Planning and Resources Development Act of 1974 was also directed at cost containment and mandated the use of uniform hospital accounting systems, a description of the financial operations and costs incurred by each hospital participating in the Medicare-Medicaid program, and the provision for a formal budget review of each participating hospital.

Throughout the mid-1970s and the Carter Administration, the Federal government at once assured the hospital industry some measure of prosperity in the sense that it would be paid for rendering services to a large block of impecunious patients, and also caused the industry anxiety in the sense that it became exposed to at least some measure of Federal control and intervention (Starr, 1982; Sapolsky, 1987; Stevens, 1989). This concern for controlling costs was demonstrated by the heavily debated Hospital Mandatory Cost Containment Program introduced by the Executive Branch in 1977. The Carter Administration's proposed cost containment program sought directly to contain both public and private reimbursements for hospitals (Abernathy \& Pearson, 1979; Sapolsky, 1987) and thus to regulate across the entire spectrum of health-care recipients. A united hospital industry (for example, the American Hospital Association and the Association of American Healthcare Systems), defeated the bill but promised in its stead self-restraint in hospital charges (Demkovich, 1979). The industry's heavy lobbying efforts finally produced a more lenient substitute bill, HR 5635, that encouraged a voluntary cost containment effort on the part of hospitals and the appointment of a study commission to consider and recommend to the hospitals various cost control measures.

Despite the presence of such cost containment legislation, however, health-care costs continued to escalate (Starr, 1982; Havighurst, 1987; Warren, 1988; Stevens, 1989). Faced with the industry's continued strong opposition to the imposition of direct, inflexible controls (Demkovich, 1979; Brown, 1988) and consistent with its campaign deregulation promises (Brown, 1988; Havighurst, 1988), the Reagan Administration offered a prospective payment proposal as a less direct way of regulating costs for those patients for whom the Federal government had direct fiscal responsibility - Medicare and Medicaid patients. Stevens (1989) defines this increasingly active Federal influence as the "New Standardization". This Federal initiative was supported by the American Hospital Association and the Federation of American Healthcare Systems. The prospective payment for health-care services legislation was signed into law in October of 1983. This Social Security Amendment states that

\footnotetext{
Medicare payments will be made at a predetermined, specific rate for each discharge. All discharges are classified according to a list of diagnosis related groups (DRGs). This list contains $\mathbf{4 7 0}$ specific categories (p. 39754). We believe that by including all inpatient operating costs, the system maintains financial incentives which will permit bospitals to plan the most efficient use of resources given their unique operating circumstances Thus, the decisions concerning the allocation of all resources rest with the managers responsible for planning care. It is only in this manner that the most effective use of health care funds can be achieved (Department of Health and Human Services, 1 September 1983, p. 39761, emphasis added).
}

Basically, PL 98-21 replaced a cost-based, retrospective reimbursement system with a diagnosis-specific prospective payment plan by which the Federal government fixed the diagnostic categories (that is, the DRGs) and payment structure for each treatment category. 
Under PL 98-21, if a hospital's costs exceed specified payment schedules for Medicare patients, the hospital must absorb the excess costs. Each DRG is defined in terms of one or more of the following variables: principal diagnosis, operating room procedures, comorbidities and complications (secondary diagnoses), age, and discharge status. Thus, the DRGs represent a multivariate system for classifying hospital patients into mutually exclusive and exhaustive groups, under the assumption that types of cases or "product lines" have similar patterns of Federal payments and also, ideally, resource consumption (Fetter \& Freeman, 1986; Averill, 1991; Fetter, 1991). By clustering patients into medically meaningful groups, PL 98-21 seeks to minimize the Federal government's Medicare expenditures. Such case-mix data can also help such third-party payers as Blue Cross to monitor differences among hospitals and to contain costs by facilitating comprehensive budget reviews (at an appropriate rate level) and charge setting (within an appropriate rate structure) for non-Medicare patients.

In turn, the hospital industry has developed case-mix accounting systems to generate information pertaining to the costs of delivering the DRG products to patients (Borden, 1988; Chandler et al., 1991). By closing the accounting circle of matching revenues (DRG-based prospective payments) with costs (isolated by case-mix accounting systems expressed in terms of the DRG structure), information ostensibly becomes available for evaluating the profitability of the various product lines and thereby guiding both resource allocation decisions and the performance appraisals of various hospital subunits and individual health-care delivery clinicians and technicians (Fetter \& Freeman, 1986; Fetter, A. et al., 1991). This approach assumes that DRG and case-mix accounting systems seek to represent faithfully the costs of the underlying task technology of health-care delivery while diagnosing the illness and delivering the service. In essence, the case-mix accounting systems developed around DRG categories merge with epidemiological and management science approaches to health administration by directly linking the costs and outcomes of providing health services and by providing incentives for cost control and efficiency (Fetter \& Freeman, 1986).

The case-mix accounting system would, in theory, provide hospital administrators with both a rigorous form of accountability and measures of production efficiency that encourage comparisons among departments and physicians, thereby establishing and documenting a relationship between medical and administrative decisions (Thompson et al., 1979; Fetter et al., 1980; Fetter, A. et al., 1991). On this point, Eastaugh (1987), for example, has suggested that hospitals could and should use DRGs and the resultant case-mix accounting information to offer only those products that promise a certain threshold of profitability. Further, patients who cannot be profitably served by any given hospital or clinician should be referred elsewhere for treatment (Fetter \& Freeman, 1986; Eastaugh, 1987). In addition, case-mix accounting systems should facilitate a number of management philosophies or techniques hospitals value: improved patient treatment scheduling; the delegation of more budgetary and accounting activities to departmental managers thus increasing budgetary participation; the deployment of the medical staff in response to patient needs; and the formation of physician cost-control committees (Cook et al., 1983, 1985; Young \& Saltman, 1983; Smith \& Mick, 1985).

\section{An extended institutional theory perspective}

Earlier, we posed the following research question:

RQ 1. To what extent are vested interests, and particularly those of the state, served by the development, implementation and modification of institutionalized organizational practices (such as case-mix accounting systems)?

An initial and general response is that one should not treat the Federal government as a monolithic entity that impartially reviews, interprets and transmits societal expectations. Rather, it is a specific entity that can exhibit self-interest (Perrow, 1985, 1986) and may thus become an 
active force in shaping and molding societal expectations. Reflecting an institutional perspective, Scott provided insight consistent with this suggestion:

\begin{abstract}
Which environmental agents are able to define the reigning forms of institutional structure will be determined largely by political contests among competing interests. Outcomes will be influenced not only by differential resources and sanctioning facilities but will also be strongly shaped by the agents' differential ability to lay successful claim to the normative and cognitive facets of the political processes: those identified by such concepts as autbority, legitimacy, and sovereignty. Outcomes will also be influenced by the structure of the state itself and its relation to the penetration of society. Organizational scholars must bring the state back in as an important institutional actor not only in its own right, but reconceptualizing as well political systems in ways that reveal the varied role that political and legal structures play in shaping the institutional frameworks within which organizations of varying types operate (1987, p. 509, emphasis added).
\end{abstract}

Through its Medicare and Medicaid programs, the Federal government has developed an abiding interest in health-care delivery; with the ever-increasing associated costs, it has also developed a keen, instrumentally rational objective of controlling those costs. But its direct or overt attempts to control costs for all patients have met strong and effective opposition from the health-care industry - particularly the American Hospital Association and the American Medical Association - that has countered with promises of voluntary cost control, promises that have subsequently failed (Abernathy \& Pearson, 1979; Demkovich, 1979). Here, the hospital industry as a subordinated agency was at first able to act collectively to achieve effective resistance (Clegg, 1989a). Withdrawing from its overt social-regulatory position of directly controlling costs for all patients, the government responded by developing an approach to covertly controlling costs by paying specific rates for specific services rendered to only Medicare and Medicaid patients amid the rhetoric of deregulating health-care delivery and supporting decentralized decision making (Brown, 1988; Havighurst, 1988).

The health-care industry initially supported this covert approach. It was, after all, apparently consistent with medical rationality, based as it was on medically meaningful diagnostic groupings of patients. It appears that DRGs and the resulting case-mix accounting systems served simultaneously first and foremost to provide an instrumental solution to controlling Federal cost outlays, and secondarily, as a political exchange by apparently depoliticizing health-care delivery through the exercise of covert rather than overt control (Fombrun, 1986). One may infer that the medical-organizational-institutional practices associated with the development, implementation and use of the DRG framework were influenced by power and self-interest of (here) the Federal government (Clegg, 1989a, b). Note, however, that the Federal government was not omnipotent, but was constrained to use a covert, surveillancebased disciplinary practice rather than the direct control of costs for all patients it at first preferred.

Extending this line of thought, Starr (1982) predicted that as a consequence of the Carter Administration's failure to rationalize and control medical services using the public-sector logic of direct regulatory intervention, health-care service delivery and the role of the Federal government therein would eventually become rationalized under the private-sector logics of commercialism and depersonalization (see also Marmor et al. , 1986). Sapolsky (1987) made the additional point that the health-care system has traditionally depended on a system of crosssubsidies: the rich subsidize the poor, the well subsidize the sick, and the young subsidize the old. Burdened by the most expensive patients, the old and the poor. the Federal government eventually sought to reduce its own costs through narrowly focused legislation that controlled costs for only Medicare and Medicaid patients, and subsequent DRG legislation that covertly controlled costs by using its legislative power to gain a special advantage for itself, thereby weakening the effect of the crosssubsidies and forcing displaced costs onto others. The Federal government enjoyed partial relief, but other private payers of significant clout like Blue Cross faced higher costs for nonMedicare patients. These private payers would 
begin actively to bargain for discounts and to seek alternative health delivery systems for its own clients, thereby forcing even greater costs on less powerful third parties or patient-payers - price takers lacking the capacity of price makers for collective action and effective resistance (Clegg, 1989a).

Hospital administrators, meanwhile, have no choice but to conform to PL 98-21 for their Medicare patients. With reference to power, the motivation lying behind this conformity is, quite understandably, to advocate for the hospital by maximizing Federal and other third-party payments. Thus, one would expect their primary focus in using the DRG-based system to be on generating, as opposed to merely internally allocating, resources. This focus on obtaining economic resources is instrumentally rational; consequently, one can see the use of DRGs by hospitals as a technological solution to its problem of obtaining scarce resources (Hackman, 1985; Perrow,1985).

The process behind this generation, which seeks to demonstrate PL 98-21 conformity, is, however, one of political advocacy (Meyer, A., 1984; Boland \& Pondy, 1983; Covaleski \& Dirsmith, 1988b). At issue is whether hospital administrators will, in fact, turn the externally directed DRG-based, case-mix-augmented accounting system inwardly to allocate resources among subunits. Given that accounting is a generally accepted if not a taken-for-granted process for guiding resource allocation decisions in a variety of organizational contexts, and that it provides the appearance of neutrality, objectivity and verifiability, it may also serve as a convenient, autoregulatory means for allocating resources internally. One may argue that the discretion for its application does not, after all, rest completely with the hospital administrators (Meyer \& Rowan, 1977; Harris, 1977; Scott \& Backman, 1990) but derives from Federal law. If it is, in fact turned inwardly, the result would be to couple external imagery and internal operating processes. On this internal use of the DRG framework and case-mix accounting, Clegg (1989b) has suggested that surveillance practices may be used as means for determining power in that such practices as the DRG framework do not provide for their own interpretation, but must rather be transformed by organizational actors - here, hospital administrators (Freidson, 1986; see also Chua \& Degeling, 1989, for a further development of this theme as it applies to the use of DRGs). Once more, case-mix accounting may be used as a political device, this time for transforming the DRG framework and case-mix accounting systems into a specific, organizationally directed surveillance practice for legitimating the allocation decisions made by administrators and, in so doing, influencing those allocations. Consequently, anticipating the $\mathrm{RQ} 2$ analysis, the existence of Federally mandated DRG payment systems carries a definite potential for penetrating backstage operating processes and revealing which departments or "product lines" get what financial resources for what purposes (Powell, 1985).

DRGs and case-mix accounting may also serve a more direct role: the redistribution of power within hospitals. As a form of what Mintzberg (1979) called "a professional bureaucracy", physicians have long acted as autonomous practitioners and have consequently long possessed organizational power (Freidson, 1986; Abbott, 1988; Scott \& Backman, 1990). For example, physicians have traditionally made unilateral admissions, treatment, length-of-stay, and discharge decisions. They have also figured prominently in hospital cost structures and are accordingly a principal target of control for casemix accounting systems. Here, amid a rhetoric extolling measures of facilitating physicians' efforts to limit unnecessary procedures and enhancing their own efficiency and effectiveness (see, for example, Thompson, 1978, 1981), case-mix accounting systems focus on isolating variances among doctors in billings to DRGdefined groups as compared to hospital or industry standards (Berki, 1983; Fetter, 1991). By making these consequences visible (Becker \& Neuhauser, 1975), administrators can covertly influence the admissions, treatment, length-ofstay and discharge decisions, thus reinforcing Clegg's (1987) emphasis on power as closely 
begin actively to bargain for discounts and to seek alternative health delivery systems for its own clients, thereby forcing even greater costs on less powerful third parties or patient-payers - price takers lacking the capacity of price makers for collective action and effective resistance (Clegg, 1989a).

Hospital administrators, meanwhile, have no choice but to conform to PL 98-21 for their Medicare patients. With reference to power, the motivation lying behind this conformity is, quite understandably, to advocate for the hospital by maximizing Federal and other third-party payments. Thus, one would expect their primary focus in using the DRG-based system to be on generating, as opposed to merely internally allocating, resources. This focus on obtaining economic resources is instrumentally rational; consequently, one can see the use of DRGs by hospitals as a technological solution to its problem of obtaining scarce resources (Hackman, 1985; Perrow, 1985).

The process behind this generation, which seeks to demonstrate PL 98-21 conformity, is, however, one of political advocacy (Meyer, A., 1984; Boland \& Pondy, 1983; Covaleski \& Dirsmith, 1988b). At issue is whether hospital administrators will, in fact, turn the externally directed DRG-based, case-mix-augmented accounting system inwardly to allocate resources among subunits. Given that accounting is a generally accepted if not a taken-for-granted process for guiding resource allocation decisions in a variety of organizational contexts, and that it provides the appearance of neutrality, objectivity and verifiability, it may also serve as a convenient, autoregulatory means for allocating resources internally. One may argue that the discretion for its application does not, after all, rest completely with the hospital administrators (Meyer \& Rowan, 1977; Harris, 1977; Scott \& Backman, 1990) but derives from Federal law. If it is, in fact turned inwardly, the result would be to couple external imagery and internal operating processes. On this internal use of the DRG framework and case-mix accounting, Clegg (1989b) has suggested that surveillance practices may be used as means for determining power in that such practices as the DRG framework do not provide for their own interpretation, but must rather be transformed by organizational actors - here, hospital administrators (Freidson, 1986; see also Chua \& Degeling, 1989, for a further development of this theme as it applies to the use of DRGs). Once more, case-mix accounting may be used as a political device, this time for transforming the DRG framework and case-mix accounting systems into a specific, organizationally directed surveillance practice for legitimating the allocation decisions made by administrators and, in so doing, influencing those allocations. Consequently, anticipating the $\mathrm{RQ}^{2}$ analysis, the existence of Federally mandated DRG payment systems carries a definite potential for penetrating backstage operating processes and revealing which departments or "product lines" get what financial resources for what purposes (Powell, 1985).

DRGs and case-mix accounting may also serve a more direct role: the redistribution of power within hospitals. As a form of what Mintzberg (1979) called "a professional bureaucracy", physicians have long acted as autonomous practitioners and have consequently long possessed organizational power (Freidson, 1986; Abbott, 1988; Scott \& Backman, 1990). For example, physicians have traditionally made unilateral admissions, treatment, length-of-stay, and discharge decisions. They have also figured prominently in hospital cost structures and are accordingly a principal target of control for casemix accounting systems. Here, amid a rhetoric extolling measures of facilitating physicians' efforts to limit unnecessary procedures and enhancing their own efficiency and effectiveness (see, for example, Thompson, 1978, 1981), case-mix accounting systems focus on isolating variances among doctors in billings to DRGdefined groups as compared to hospital or industry standards (Berki, 1983; Fetter, 1991). By making these consequences visible (Becker \& Neuhauser, 1975), administrators can covertly influence the admissions, treatment, length-ofstay and discharge decisions, thus reinforcing Clegg's (1987) emphasis on power as closely 
associated with the interpretation and application of a set of rules and disciplinary practices (see also DiMaggio, 1988; Zucker,1988b).

The foregoing analysis brings together strands of thought susceptible to further analysis in future research. The DRG framework appears to be more than merely a passive medium for expressing societal expectations (Meyer \& Rowan, 1977). It also provides more than mere additional justification for case-mix accounting, which further embodies and expresses these expectations. Rather, the DRG and case-mix accounting phenomena appear to be, themselves, infused with power and self-interest (Perrow, 1985; Powell, 1985; DiMaggio, 1988). The arguments advanced primarily by Clegg (1987, 1989a, b) suggest that the DRG framework and the related case-mix accounting systems may be interpreted as means for effecting macro- and micro-surveillance in which individuals (both physicians and patients), collectives (departments, individual hospitals and classes of hospitals) and services (as organized into "product lines") are categorized and discriminated through apparently objective calculations that form a virtually anonymous discipline strategy. As a form of disciplinary practice, the framework inscribes and normalizes hospitals, clinicians, and patients as well. The DRG framework and related case-mix accounting systems appear also to determine power by redistributing that power from physician to administrator. Together, the DRG and case-mix accounting phenomena may be seen as two variants of disciplinary practice that calculate macro, societal-level (that is to say, the Federal government) and micro, organizationlevel (the hospitals) rationality from the distinct auspices of power.

Viewed as an unfinished process in which the DRG and case-mix accounting phenomena currently operate, institutionalization appears to be infused with power and vested interests in the health-care environment. The DRG framework and case-mix accounting appear to serve simultaneously as (1) technological solutions to the Federal government's need to control its health-care cash outlays; (2) a political ex- change allowing the government to act covertly in its own self-interest in a seemingly apolitical way, to determine power, and to enable hospital administrators to redistribute power in the name of objectivity, efficiency and profitability; and (3) a means of social discourse expressing the government's need to control health-care costs to hospitals and to departments and individual health practitioners in a way that health-care providers can accept or at least resist only ineffectively.

On this latter point pertaining to the ability to resist, we earlier posed the following research question:

RQ 2. To what extent do institutionalized legitimation practices (in the current context, case-mix accounting systems developed in response to DRG payment systems ) penetrate and influence internal organizational practices?

Consistent with the theme already advanced with regard to power - that such disciplinary and surveillance practices as the DRG framework and case-mix accounting define and normalize the activities of both organized bodies and individuals (Clegg, 1989a, b) - one can partition the answer to this question on three related levels as concerning hospitals, departments and patients (see Tolbert, 1988, who concluded that the issue of decoupling can be addressed only by concentrating on the microor organization-level effects of institutionalized practices).

At the first level of analysis, the exercise of power necessarily involves both obedience to disciplinary practices and reciprocal resistance (Clegg, 1989b), where effective resistance contributes to the decoupling between institutionalized practices and internal operations. Just as the exercise of power need not be overt, effective resistance by the subjects of control may involve covertly circumventing or diverting disciplinary practices to their own ends. In such cases, the relative power of, or resources deployed by, those being controlled determines the effectiveness of the resistance. From an institutional theory perspective, Scott (1987, p. 509) described this precise situation, arguing 
that the outcomes of institutionalization are shaped by both the differential resources and the ability to lay successful claim to the normative and cognitive facets of the political processes.

Ascribing to this reasoning, Sapolsky (1987) observed that private, financially stronger hospitals having a relatively diverse resource base could use case-mix accounting data to screen patients and admit or "skim" only the more profitable ones (Fetter \& Freeman, 1986; Eastaugh, 1987). Here, the similarity to Starr's (1982) prediction that the private-sector logic of commercialism and depersonalization would one day influence health care is particularly striking. In part, Sapolsky reasoned, the screening would be abetted by such large insurers as Blue Cross:

Discount-seeking payers encourage the "skimming" of patients from hospitals by entrepreneurial ventures such as those that create medicine's newest and most lucrative specializations. With the growing surplus of physicians, it is easier and easier to promise large payers bargains by providing services in specialized settings unencum bered by the reserve capacity and costly overheads needed to maintain tertiary care facilities. Bargains for some, no doubt, but this pattern of stripping away profitable clients destroys the complex web of crosssubsidies that in large part supports teaching and services for the poor and for those with rare or expensive illnesses (1987, p. 70 ).

Thus, one can find a dark aspect of DRGs and case-mix accounting on the bright side of profits. Concerning this darkness, Sapolsky effectively argued that such financially strained facilities as inner-city hospitals, as well as employers and insurers unable to resist covert regulation, are more heavily affected by the DRG phenomenon because they increasingly attract more of the most costly patients, whose related revenue is fixed by DRG payment schedules, than the attractive patients the more profitable institutions accept:

Small employers and insurers are not the only potential victims of [the] "beggar thy neighbor" strategy. Some hospitals lack a sufficient number of privately insured patients to absorb the losses sustained in meeting government demands for price advantages. Especially vulnerable are inner city hospitals that serve the uninsured and that often maintain expensive teaching programs (1987, p. 70). [While DRG payments are based on average cost per category for average patients for average stays, the poor and elderly are liable to be above average in all categories.]

Consistent with Scott's (1987) and Clegg's (1989a, b) positions, profitable hospitals seem more liable to "skim" patients and in so doing lay cognitive claim to the normative and cognitive facets of the DRG system. It seems certain that the social network of hospitals will be affected thereby, and one could infer that the decoupling between external symbolic displays and internal operating processes will be influenced by the differential resource munificence or scarcity of hospitals: the financially strained hospitals would receive relatively few resources while the backstage operating processes for the profitable hospitals would enjoy a decoupling from their external legitimation practices of adopting the DRG framework and case-mix accounting systems.

At the second level of analysis, one can generally expect that effective resistance to or decoupling from the disciplinary practices of the DRG and case-mix accounting phenomena will be conditioned by the differential resources of the departments within hospitals. In support of this expectation, empirical research on budgeting (see, for example, Pfeffer \& Salancik, 1974; Hills \& Mahoney, 1978; Hackman, 1985; Covaleski \& Dirsmith, 1988b) suggests that accounting information plays more of a political advocacy role in organizations characterized by financial hardship. More specifically, Hackman (1985) found that a subunit with high visibility among external constituents and a concomitant ability to acquire the external resources needed by the organization, strongly influenced internal resource allocations and gained for itself a disproportionate share of those internal resources. Extending this line of thought with respect to power, whereas financially strong hospitals may effectively decouple external imagery from backstage operating processes, possibly by carefully skimming profitable patients (Eastaugh, 1987; Sapolsky, 1987), poorer hospitals may 
expect different departments to generate differential revenues, incur differential costs and earn differential profits. Thus, departments may exhibit a differential ability to help hospital administrators perform their advocacy or revenue generating functions. Consistent with the prescriptions of orthodox commentators like Fetter \& Freeman (1986) and Eastaugh (1987), administrators may then be expected to allocate an increased proportion of resources to departments that help generate the most resources, thus at once recognizing and augmenting the internal power of those departments.

To the extent that the institutionalized DRG framework and the resultant case-mix accounting system influence the internal allocation of resources, external imagery can penetrate and alter backstage operating processes in financially strained hospitals. From the perspective of the department heads, the use of DRGs and casemix accounting to demonstrate profitability appears simultaneously to be a means of political exchange and a technological solution wherein their own effective support of the system both permits hospital administrators to perform their advocacy function so as to generate resources externally, and facilitates their own advocacy role insofar as they receive a greater portion of those resources that are, in turn, deployed in treating patients.

As we noted earlier in our discussion of power, an imposition of the DRG framework and case-mix accounting may contribute to the transfer of admission, treatment, length-of-stay and discharge decisions from physicians to administrators who are, in turn, supported by these seemingly neutral objective surveillance practices (Freidson, 1986). Thus, these two phenomena exemplify the encoding expertise in a hospital's organizational structure and away from individuals (Abbott, 1988). The potential transfer of these four critical patient-treatment decisions suggests a potential for affecting the very health of patients. On this point, Shortell and Hughes observed that

There is growing concern that, as hospitals are increasingly buffeted by external pressures to reduce costs, they may be forced to allocate resources in ways that could adversely affect patients' care. Under the Medicare prospective payment system, for instance, hospitals have incentives to discourage the admission of beneficiaries with high costs, to reduce the diagnostic and therapeutic resources used for these beneficiaries, and to discharge them sooner. [Witness Eastaugh's (1987) and Young \& Saltman's (1983) positions in advocating DRG-systems discussed earlier.] Any one of these responses could result in adverse outcomes. Anecdotal evidence suggests that such adverse outcomes may already be occurring (1988, p. 1101).

In an effort to augment this anecdotal evidence, Shortell \& Hughes (1988) conducted an empirical analysis of 214,839 discharges from 981 hospitals. They found a significant association between higher mortality rates among inpatients, and (a) the stringency in state programs of hospital rate reviews (closely associated with DRG rates where case-mix accounting information guides an evaluation of the rates); (b) the stringency of certificate-of-need legislation; and (c) the intensity of competition in the healthcare marketplace (this latter finding suggests support for Sapolsky's, 1987, profitable patient "skimming" argument). Shortell and Hughes found that hospitals in states with stringent rate reviews produced death rates $6-10 \%$ higher than hospitals in less stringent states. One may infer that societal expectations, as expressed in the form of externally directed, DRG-based symbolic displays, can in fact penetrate external operating processes and affect the patients themselves (Powell, 1985).

\section{IMPLICATIONS AND CONCLUDING DISCUSSION}

In contrast with the orthodox perspective, which asserts that accounting in general (for example, Ijiri, 1965; Horngren, 1977; Cooper \& Kaplan, 1991) and the DRG framework and casemix accounting systems in particular (for example, Fetter \& Freeman, 1986; Cook et al., 1983, 1985; Havighurst, 1987; Fetter, A. et al., 1991) faithfully represent an organization's economic or technical reality, institutional theory (for example, Meyer \& Rowan, 1977; 
DiMaggio \& Powell, 1983) offers compelling insights into the social and behavioral facets of these surveillance practices. This perspective suggests that one cannot understand such organizational and regulatory practices as the DRG framework and case-mix accounting merely with reference to the general rationality of their structural properties. On this point, Clegg argued that

\begin{abstract}
Organizations should not be conceptualized as the phenomenal expression of some essential inner principle such as economic exploitation or rationality.... One cannot explain the politics of all organizations in terms of general theories of their rationality. Organizational action is an indeterminate outcome of substantive struggles between different agencies: between people who deploy different resources; people whose organizational identities will be shaped by the way in which disciplinary practices work through and on them, even in their use of such techniques; people who seek to control and decide the nature of organizational action. Consequently, the interests of actors in organizations and the decisions that they make are necessarily contingent on various forms of organization calculation. Thus, organizational action cannot be the expression of some essential inner principle: claims to such principles as prime movers necessarily neglect the actual complex and contingent conditions under which organizational action occurs (1989b, p. 105).
\end{abstract}

Consistent with this position, we conclude that one can more accurately characterize such practices as the DRG framework and case-mix accounting as social in nature, practices whose principal purpose is at once to express and demonstrate a conformity with institutionalized rules and expectations (Meyer \& Rowan, 1977; DiMaggio \& Powell, 1983).

Our analysis also suggests that the two criticisms made of institutional theory dealing with power and decoupling and expressed as our two research questions tend to be interrelated. Moreover, at least as one interprets them in a health-care context, hierarchical order is implicit in them. More specifically, power emerges as the important dynamic that conditions the issue of decoupling (Perrow, 1985, 1986; Powell, 1985; Clegg, 1989a, b). Because the DRG framework and related case-mix accounting systems undergo continual refine- ment as hospitals implement and use them, they may be seen as unfinished processes infused with power, rather than merely as outcomes beyond the reach of vested interests (DiMaggio, 1988; Clegg, 1989a, b). Here, the analysis suggests that the Federal government could not exercise power overtly to reflect its own selfinterest because of the force with which the hospital industry opposed that intrusion. Instead, the government deployed a formal, structural surveillance practice - the DRG framework developed in part by the hospital industry itself, to reflect its interest indirectly without arousing active resistance (Scott, 1987). This exercise was covert and, perhaps consequently, effective (Burns, 1986).

It follows that the use of such disciplinary and surveillance practices represents one of the subtlest and most effective tools for influencing if not controlling a social situation, an adroit substitute for the overt use of power, the very deployment of which might actually signal weakness (Pfeffer, 1981; Edelman, 1977; Hopwood, 1984). Here, the Federal government manifested true power by excusing hospitals from cost-cutting efforts they otherwise would not have undertaken, but then convincing the hospitals to undertake these efforts voluntarily. Though these rules and disciplinary and surveillance practices were cloaked in the appearance of objectivity and neutrality, the interested parties who are both game players and referees had yet to interpret them; the interpreting act, of course, establishes and maintains the hierarchies of authority and status (Clegg, 1989a, b). Clegg concluded that such organizations as hospitals survive by conforming to those interests that are hierarchically superior, like the state, in part by conforming to their disciplinary and surveillance practices, demonstrating this conformity externaliy, and reaffirming their efficacy internally.

Within individual hospitals, the institutionalization of DRGs as an ongoing process appears to be similarly political. Hospital administrators may use the DRG framework to advocate for the hospital and to help generate resources - acts both broadly rational and political (Alan Meyer, 
1984; Hackman, 1985). But this advocacy is at once determined by and determines power as expressed by the availability of existing resources and the capacity to lay cognitive claim to (Scott, 1987) and divert to its own purposes (Clegg, 1989a, b), the DRG framework. More specifically, financially stronger hospitals, the profitable and for-profit ones, have the capacity to "skim" (Sapolsky, 1987) those types of patients who receive a profitable "product line" of services, leaving unprofitable patients, largely the poor and the elderly, to be served by financially weak hospitals without the ability to divert the DRG framework.

Within individual hospitals, the institutionalization of the DRG framework and case-mix accounting systems as ongoing processes also appears to be profoundly political and potentially complicit in a shift in the balance of power from the practitioner to the administrative components of the hospitals (Freidson, 1986) and among departmental units. To begin with, DRGbased case-mix accounting was developed and implemented by the industry to facilitate the allocation of resources internally as well as to provide a convenient, apparently objective, and neutral cost containment discourse. With the revenue and cost consequences of a physician's admission, treatment, length-of-stay and discharge decisions made more visible (in DRG payments and as revealed by case-mix accounting), power shifts from the physician to the hospital administrator (Clegg, 1989a, b; Freidson, 1986) in the sense that expertise becomes encoded within organizational structure rather than in the individual (Abbott, 1988).

In addition, one can associate the deployment of these systems with a shift in resource allocation toward departmental units having higher visibility among external constituents, as evidenced by their ability to generate more revenues for the hospital - all of which couples external imagery and backstage process. Consistent with this theme, departmental managers, whose effectiveness depends on how profitably they manage their DRG categories and with varying abilities to lay cognitive claim (Scott, 1987 ) to these two surveillance practices and divert them to their own ends (Clegg, 1989a, b), may use case-mix accounting information to advocate for the subunit and gain more resources.

Accounting, in such a situation, is both rational and covertly political. That is, case-mix accounting information may both provide a technical solution to the rationalistic goal of generating more resources and serve as a means of fostering political exchanges wherein social actors redistribute power. But here too, the relative financial strength of the hospital may well mitigate both the power dynamics of deploying case-mix accounting and the extent to which external imagery penetrates and alters backstage operating processes. Profitable hospitals may be able to decouple their external imagery from internal processes by actively screening patients, and in so doing avoid the need to exercise power internally. Financially weaker (typically, urban) hospitals generally cannot divert the DRG and case-mix accounting surveillance practices to their own ends (Clegg, 1989a, b).

We conclude that the institutional perspective contributes significant insights to the development and implementation of the DRG framework and case-mix accounting in the American health-care context and that this context, in turn, provides a unique opportunity for extending institutional theory. ${ }^{2}$ We recommend

\footnotetext{
${ }^{2}$ This analysis used institutional theory to widen the conceptualization of the DRG framework and case-mix accounting. But, the analysis is relatively provincial in that it examined only the U.S. health-care environment. The DRG framework is being exported to other countries, which use the same basic treatment categories, sometimes fortified by and sometimes lacking case-mix accounting systems. Because this framework now appears around the world and in some countries that use different accounting systems, the DRG framework offers an ideal opportunity to study institutionalization internationally. Meyer (1986) noted that accounting as an institutionalized process may be expected to vary systematically in different national societies. For example, the U.S. reflects both an accounting and a legal orientation, while the U.K. reflects more of an accounting than a legal orientation, Germany reflects more of a legal than an accounting orientation, and France
} 
future research be directed at examining (a) institutionalization as an ongoing process - in that the DRG framework and case-mix accounting are currently being implemented and refined in numerous health-care delivery organizations - rather than as an outcome; (b) the complicity of the DRG framework and casemix accounting in the covert exercise of power, where that power is expressed in terms of resource availability and scarcity and the ability to lay cognitive claim to these two surveillance practices and divert them to various interested parties; and (c) the extent to which power conditions the decoupling that may take place between external imagery and internal social and technical operating processes.

\section{BIBLIOGRAPHY}

Abbott, A., The System of Professions (Chicago: University of Chicago Press, 1988).

Abernathy, D. S. \& Pearson, D. A., Regulatory Hosptial Costs: Their Development of Public Policy (Ann Arbor, MI: AUPHA Press, 1979).

Averill, R., Development, in Fetter, R. (ed.), DRGs (Ann Arbor: Health Administration Press, 1991 ).

Becker, S. \& Neuhauser, D., The Efficient Organization (New York: Elsevier, 1975).

Benveneste, G., Professionalizing the Organization: Reducing Bureaucracy to Enbance Effectiveness (San Francisco: Jossey-Bass, 1987).

Berki, S. E., The Design of Case-Based Hospital Payment Systems, Medical Care (1983) pp. 1-13.

Boland, R. J., Jr \& Pondy, L. R., Accounting in Organizations: a Union of Natural and Rational Perspectives, Accounting, Organizations and Society (1983) pp. 223-234.

Borden, J. P., An Assessment of the Impact of Diagnosis-Related Group (DRG) Based Reimbursement on the Technical Efficiency of New Jersey Hospitals Using Data Envelopment Analysis, Journal of Accounting and Public Policy (1988) pp. 77-96.

Brown, L. D., Introduction to a Decade of Transition, in Brown, L. D. (ed.), Health Policy in Transition, pp. 1-16 (Durham, NC: Duke University Press, 1988).

Burns, T. R., Actors, Transactions and Social Structures, in Hemmelstrand, V. (ed.), Sociology: From Crisis to Science? Vol. 2, pp. 8-37 (London: Sage, 1986).

Chandler, I., Fetter, R. \& Newbold, R., Cost Accounting and Budgeting, in Freeman, R. (ed.), DRGs (Ann Arbor: Health Administration Press, 1991).

Chua, W. F. \& Degeling, P., Health Care Cost Control in the U.S. Through the Used DRGS and Prospective Payment: a Case-Study of Positivity, Discipline and Resistance, Working paper, University of New South Wales (September 1989).

Clegg, S. R., The Language of Power and the Power of Language, Organization Studies (1987) pp. 61-70.

Clegg, S. R., Framework of Power (London: Sage, 1989a).

Clegg, S. R., Radical Revisions: Power, Discipline and Organizations, Organization Studies (1989b) pp. 97-115.

Cook, K, Shortell, S. M., Conrad, D. A. \& Morrisey, M. A., A Theory of Organizational Response to Regulation: the Case of Hospitals, Academy of Management Review (1983) pp. 193-343.

Cook, K., Shortell, S. M., Conrad, D. A. \& Morrisey, M. A., A Theory of Organizational Response to Hospital Regulation: a Reply to Smith and Mick, Academy of Management Review (1985) pp. 337-343.

reflects more of a bureaucratic than an accounting orientation. If this speculation is sound, and given the similarity of the DRG framework across countries, one could fruitfully examine the relative impact of this framework vis-à-vis accounting versus legal structural properties versus bureaucratic structural properties. Currently, research conducted independently by Borden (1988), Chua \& Degeling (1989), and Rea \& Cooper (1989) suggests that the implementation of DRGs as an institutionalized process is proceeding differently in the U.S., Australia and the UK, respectively. Future research may usefully explore any systematic variation in the impact of the DRG framework in an integrated manner, consistent with Meyer's (1986) theorizing. Here too, the power dynamics that inheres in the U.S.'s exportation of this surveillance practice across national boundaries, and particularly to developing countries, would bear examination. 
Cooper, R. \& Kaplan, R., The Design of Cost Management Systems (Englewood Cliffs, NJ: Prentice Hall, 1991).

Covaleski, M. A. \& Dirsmith, M. W., The Use of Budgetary Symbols in the Political Arena: an Historically Informed Field Study, Accounting, Organizations and Society (1988a) pp. 193-214.

Covaleski, M. A. \& Dirsmith, M. W., An Institutional Perspective of the Rise, Social Transformation and Fall of a University Budget Category, Administrative Science Quarterly (1988b) pp. 562-588.

Demkovich, L. E., Who Can Do a Better Job of Controlling Hospital Costs? National Journal (1979) pp. 219-223.

Department of Health and Human Services, Federal Register: Part Four - Healtb Care Financing Administration; Medicine Program; Prospective Payments for Medicine Inpatient Hospital Services; Interim Final Rule with Comment Period (Washington, DC: U.S. Government Printing Office, 1 September 1983).

DiMaggio, P. J., Interest and Agency in Institutional Theory, in Zucker, L. (ed.), Institutional Patterns and Organizations: Culture and Environment, pp. 3-21 (Cambridge, MA: Ballinger, 1988).

DiMaggio, P. J. \& Powell, W. W., The Iron Cage Revisited: Institutional Isomorphism and Collective Rationality in Organizational Fields, American Sociological Review (1983) pp. 147-160.

Eastaugh, S., Financing Health Care (Dover, MA: Auburn House, 1987).

Edelman, J. M., Political Language: Words that Succeed and Policies that Fail (New York: Academic Press, 1977).

Fennell, M. L. \& Alexander, J. A., Organizational Boundary Spanning in Institutionalized Environments, Academy of Management Journal (1987) pp. 456-476.

Fetter, A., Harms, E. \& Fetter, R., Cost-Variance Analysis, in Fetter, R. (ed.), DRGs (Ann Arbor: Health Administration Press, 1991).

Fetter, R., Background, in Fetter, R. (ed.), DRGs (Ann Arbor: Health Administration Press, 1991).

Fetter, R. \& Freeman, J. L., Diagnosis Related Groups: Product Line Management Within Hospitals, Academy of Management Review (1986) pp. 41-54.

Fetter, R., Shin, Y., Freeman, J. L., Averill, R. F. \& Thompson, J. D., Case Mix Definition by DiagnosisRelated Groups, Medical Care (supplement 1980).

Freidson, E., Professional Powers: a Study of the Institutionalization of Formal Knowledge (Chicago: University of Chicago Press, 1986).

Hackman, J. D., Power and Centrality in the Allocation of Resources in Colleges and Universities, Administrative Science Quarterly (1985) pp. 61-77.

Hall, R. H., Organizations: Structure and Powers (Englewood Cliffs, NJ: Prentice Hall, 1972).

Harris, J., The Internal Organization of Hospitals: Some Economic Implications, Bell Journal of Economics (1977) pp. 467-482.

Havighurst, C. C., The Changing Locus of Decision Making in the Health Care Sector, in Brown, L. D. (ed.), Health Policy in Transition, pp. 129-168 (Durham, NC: Duke University Press, 1987).

Hills, F. S. \& Mahoney, T., University Budgets and Organizational Decision Making, Administrative Science Quarterly (1978) pp. 454-465.

Hopwood, A. G., Accounting and the Pursuit of Efficiency, in Hopwood, A. G. \& Tomkins, C. (eds), Issues in Public Sector Accounting, pp. 167-187 (Oxford: Philip Allan, 1984).

Horngren, C. T., Cost Accounting: a Managerial Emphasis (Englewood Cliffs, NJ: Prentice Hall, 1977).

Ijiri, Y., Management Goals and Accounting for Control (New York: North Holland, 1965).

Levitt, B. \& Nass, C., The Lid on the Garbage Can: Institutional Constraints on Decision Making in the Technical Core of College Text Publishers, Administrative Science Quarterly (1989) pp. 190-207.

Marmor, T. R., Schlesinger, M. \& Smithey, R. W., A New Look at Nonprofits: Health Care Policy in a Competitive Age, Yale Journal of Regulation (1986) pp. 313-349.

Meyer, A., Mingling Decision-Making Metaphors, Academy of Management Review (1984) pp. 6-17.

Meyer, J. W., On the Celebration of Rationality: Some Comments on Boland and Pondy, Accounting Organizations and Society (1983) pp. 235-240.

Meyer, J. W., Social Environments and Organizational Accounting, Accounting, Organizations and Society (1986) pp. 345-356.

Meyer, J. W. \& Rowan, B., Institutional Organizations: Formal Structures as Myth and Ceremony, American Journal of Sociology (1977) pp. 310-363.

Mezias, S. J., An Institutional Model of Organizational Practice: Financial Reporting at the Fortune 200, Administrative Science Quarterly (1990) pp. 431-457.

Mintzberg, H., The Structuring of Organizations (Englewood Cliffs, NJ: Prentice-Hall, 1979).

Noble, L., Healthcare Reform Stews in Congressional Pressure Cooker, Healthcare Financial Management (1992) pp. 21-39. 
Perrow, C., Review Essay: Overboard with Myth and Symbols, American Journal of Sociology (1985) pp. 151-155.

Perrow, C., Complex Organizations (New York: Random House, 1986).

Pfeffer, J., Power in Organizations (Marshfield, MA: Pitman, 1981).

Pfeffer, J. \& Salancik, G., Organizational Decision Making as a Political Process: The Case of a University Budget, Administrative Science Quarterly (1974) pp. 135-151.

Powell, W. W., The Institutionalization of Rational Organizations, Contemporary Sociology (1985) pp. $564-566$.

Powell, W. W., Institutionalization Effects on Organizational Structure and Performance, in Zucker, L. G. (ed.), Institutional Patterns and Organizations, pp. 115-136 (Cambridge, MA: Ballinger, 1988).

Raelin, J. A., The Clash of Cultures: Managers and Professionals (Boston, MA: Harvard Business Press, 1986).

Rea, D. M. \& Cooper, D., Struggling with Accounting and Reason: Resource Management the National Health Service, Working paper, University of Manchester Institute of Science \& Technology (1989).

Sapolsky, H. M., Prospective Payment in Perspective, in Brown, L. D. (ed.), Health Policy in Transition, pp. 65-77 (Durham, NC: Duke University Press, 1987).

Scott, W. R., The Adolescence of Institutional Theory, Administrative Science Quarterly (1987) pp. 493511.

Scott, W. R. \& Backman, E., Institutional Theory and the Medical Care Sector, in Mick, S. (ed.), Innovations in Health Care Delivery (San Francisco: Jossey-Bass, 1990).

Scott, W. R. \& Black, B., The Organization of Mental Health Services: Societal and Community Systems (Beverly Hills, CA: Sage, 1986).

Scott, W. R. \& Meyer, J. W., The Organization of Social Sectors, in Meyer, J. W. \& Scott, W. R. (eds), Organizational Environments, Ritual and Rationality, pp. 129-153 (Beverly Hills, CA: Sage, 1983).

Shortell, S. M. \& Hughes, E. F. X., The Effects of Regulation Competition, and Ownership on Mortality Rates Among Hospital Inpatients, The New England Journal of Medicine (April 1988) pp. 1100-1107.

Smith, H. L. \& Mick, S. S., A Theory of Organizational Response to Hospital Regulation: a Reply, Academy of Management Review (1985) pp. 332-336.

Starr, P., The Social Transformation of American Medicine (New York: Basic Books, 1982).

Stevens, R., In Sickness and in Wealth (New York: Basic Books, 1989).

Thompson, J. D., Epidemiology and Health Services Administration: Future Relationships in Practices and Education, Millbank Memorial Fund (1978) pp. 253-273.

Thompson, J. D., DRGs Broaden Hospitals' Accountability and Responsibility, Hospital Progress (1981) pp. $46-49$.

Thompson, J. D., Averill, R. F. \& Fetter, R. B., Planning, Budgeting and Controlling - One Look at the Future: Case-Mix Cost Accounting, Health Services Research (1979) pp. 111-125.

Tolbert, P. S., Institutional Sources of Organizational Culture in Major Law Firms, in Zucker, L. (ed.), Institutional Patterns and Organizations: Culture and Environment, pp. 101-113 (Cambridge, MA: Ballinger, 1988).

Warren, D., News and Notes, Journal of Health Politics, Policy and Law (1988) pp. 391-398.

Young, D. W. \& Saltman, R. B., Prospective Reimbursement and the Hospital Power Equilibrium: a Matrixbased Management Control System, Inquiry (1983) pp. 20-33.

Zucker, L. G., Institutional Theories of Organization: Conceptual Development and Research Agenda, in Zucker, L. G. (ed.), Institutional Patterns and Organizations: Culture and Environment, pp. xiii-xix (Cambridge, MA: Ballinger, 1988a).

Zucker, L. G., Where Do Institutional Patterns Come From? in Zucker, L. G. (ed.), Institutional Patterns and Organizations: Culture and Environment, pp. 23-49 (Cambridge, MA: Ballinger, 1988b). 